\title{
城市建成区河流生态功能评价及修复策略 以深圳市大沙河为例
}

\author{
付贵萍 ${ }^{1}$, 赵 林 $^{1}$, 武金发 ${ }^{1}$, 胡章立 ${ }^{1}$, 胡 凯 ${ }^{2}$, 董 芸 ${ }^{2}$
}

1) 深圳大学生命与海洋科学学院, 深圳市海洋生物资源与生态环境重点实验室, 广东深圳 518055 ;

2) 深圳市河道管理中心，广东深圳 518036

摘 要：随着城市化和国民经济的高速发展，河流生态功能受到严重威胁，为评价城市建成区河流的 生态功能现状, 为后续生态修复与海绵城市规划提供理论依据, 以深圳市大沙河为例, 采用以水生生物为 核心的指标评价法对水文、水质、生境和生物多样性维持 4 项功能的 10 个指标、14 个指数进行具体评价, 并通过层次分析法计算权重, 构建河段尺度下的河流生态功能评价指标体系, 对大沙河生态功能进行评价. 结果表明, 大沙河中游受人类活动干扰较小, 具有较健全的生态功能, 为 II 级河段; 上游和中上游区域为 III级, 部分生态功能受到威胁; 下游河口段为 IV 级河段, 受人为影响严重. 结合生态功能评价结果, 对各 河段提出了针对性的生态修复策略，并从污染物、生物物种管理、生态系统的调控及市民的科普教育等多 个维度提出了河流生态系统管理措施. 研究结果可为城市建成区河流的生态功能评价与生态修复及海绵城 市建设提供依据与参考。

关键词：修复生态学；城市河流；河流生态系统；生态调查；水生生物；生态功能评价；修复策略 中图分类号：X171 文献标志码：A doi：10.3724/SP. J. 1249.2020.04372

\section{Ecological function evaluation and restoration strategy of rivers in urban built-up areas : a case study of the Dasha River in Shenzhen}

\author{
FU Guiping ${ }^{1}$, ZHAO Lin ${ }^{1}$,WU Jinfa ${ }^{1}$, HU Zhangli ${ }^{1}$, \\ HU Kai ${ }^{2}$, and DONG Yun ${ }^{2}$
}

1) College of Life Sciences and Oceanography, Shenzhen Key Laboratory of Marine Bioresource and Eco-environmental Science, Shenzhen University, Shenzhen 518055, Guangdong Province, P. R. China

2) Shenzhen River Management Center, Shenzhen 518036, Guangdong Province, P. R. China

\begin{abstract}
With the rapid development of urbanization and national economy, the ecological function of rivers has been seriously threatened. In order to evaluate the present situation of ecological function of rivers in urban built-up areas and provide theoretical basis for subsequent river ecological restoration and sponge city planning, we carry out a case study of the Dasha River in Shenzhen city. We construct the ecological function evaluation index system at the

Received: 2019-11-04; Accepted: 2020-01-10

Foundation: The 13th Five Year Marine Economy Demonstration City of the State Oceanic Administration (086); Basic Research Project of Shenzhen Knowledge Innovation Program (JCYJ20180207144018216)

Corresponding author: Professor FU Guiping. E-mail: fugp@ szu.edu.cn

Citation: FU Guiping, ZHAO Lin, WU Jinfa, et al. Ecological function evaluation and restoration strategy of rivers in urban built-up areas: a case study of the Dasha River in Shenzhen $[\mathrm{J}]$. Journal of Shenzhen University Science and Engineering, 2020, $37(4): 372-380$. (in Chinese)
\end{abstract}


reach scale for the Dasha River, in which 10 indicators and 14 indexes of four functions of hydrological support, water environment sustainment, habitat and biodiversity maintenance are evaluated by index evaluation method with aquatic organisms as the core. The index weight is calculated by the analytic hierarchy process method. The results show that the middle reach of the Dasha River is in class II level, which is less disturbed by human activities and has relatively integral ecological functions. The upper and middle upper reaches are class III areas and some ecological functions are threatened. The lower estuary section is class IV reach, which is seriously affected by human activities. Combing with the evaluation results of ecological function, we put forward the ecological restoration strategies for each reach, and suggest the daily management measures from the aspects of pollutant, biological species management, ecosystem regulation, and public education. This study provides basis and guidance for the evaluation and restoration of the ecological function and the sponge city construction in urban built-up areas.

Key words : restoration ecology; urban river; river ecosystem; ecological survey; aquatic organism; ecological function evaluation; restoration strategy

河流是城市的血脉，也是城市重要的景观要 素，具有它存水源、防洪排涝和交通航运等作用， 更是城市重要的生态廊道 ${ }^{[1]}$. 城市河流在海绵城市 建设中具有重要角色, 如何通过自然途径与人工措 施相结合，在确保城市排水防涝安全的前提下，最 大限度地利用城市河流实现雨水在城市区域的积 存、渗透和净化，促进雨水资源的利用和生态环境 保护已引起广泛关注. 但城市化的快速推进对河流 生态系统的健康构成了严重威胁，导致河流水质恶 化、水文调节功能丧失以及生物多样性锐减等问 题 ${ }^{[2]}$. 目前，约占地球表面 $2 \%$ 的城市地区却拥有 地球上退化最严重的生态系统 ${ }^{[3]}$. 因此，如何有效 评估城市建成区河流生态功能，提出针对性的修复 对策已成为当今城市河流生态系统管理与海绵城市 规划的重要议题.

目前，许多学者针对城市化背景下的河流生态 功能进行了广泛探讨 ${ }^{[4-7]}$, 常用的评价方法有模型 法、价值评价法和指标评价法，如西班牙的河岸植 被质量指数 (qualitat del bosc de ribera, QBR $)^{[8]}$ 、英 国的水环境健康预测评价模型 (river invertebrate prediction and classification system, RIVPACS $)^{[9]}$ 、澳 大利亚的河流评价系统 (Australian river assessment scheme, AUSRIVAS $)^{[10]}$ 、丹麦的 5-S-model ${ }^{[11]}$ 以及 瑞典的河岸、河道与环境指数 (riparian, channel and environmental, RCE) ${ }^{[12]}$ 等. 其中, 指标评价法是采 用最多的一种河流生态功能评价方法，中国也有诸 多学者采用该方法对长江流域 ${ }^{[13-14]}$ 、淮河流域 ${ }^{[15]}$ 、 新安江流域 ${ }^{[16]}$ 及太子河流域 ${ }^{[17]}$ 进行研究. 水质、 河岸带状况、水文和河道形态是多数研究者重点考 虑的因素. 指标评价法通常结合研究区域的生态管 理需求，目的性强，更适于管理应用. 但指标评价
法也存在一些不足: 关注河流的自然功能较多, 而 忽略了河流的社会功能 ${ }^{[17]}$; 河流生态功能评价的 河流空间尺度往往较大，而忽略了小尺度河流 ${ }^{[17]}$; 在研究对象上倾向于选取水流连续性好的河流，忽 略人工管控下河流水源结构现状与闸、坝阻隔的间 断性河流 ${ }^{[18]}$. 此外, 以水生生物为核心的河流生 态功能评价指标体系尚不多见. 因此, 现有的指标 体系法较难适用于城市建成区的河流生态功能 评价.

深圳市拥有大小河流 310 余条, 大多为流程 短、径流量小的雨源性河流, 流域大于 $100 \mathrm{~km}^{2}$ 的 只有 13 条 ${ }^{[19]}$. 其中，位于南山区的大沙河，自 1989 年起经过截污、补水和绿化等整治工程, 河道 的生境不断地更迭，区域内生物也遭受了不同程度 的胁迫，整治后的河道生态状况尚不明晰. 本研究 在吸取并改进相关指标评价体系基础上，结合河流 特征, 采用以水生生物为主, 河流自然功能为辅的 多因子综合评价法，评价河段尺度下的大沙河河流 生态功能状况, 提出针对性的修复对策, 为城市建 成区河流的生态功能评价和河流生态系统管理提供 参考.

\section{1 调查区域概况}

大沙河发源于深圳市西部的羊 (阳) 台山 (海拔 $587.3 \mathrm{~m})$, 流域面积 $92.99 \mathrm{~km}^{2}$, 干流长 $13.7 \mathrm{~km}$, 其中, 感潮河段长 $3.6 \mathrm{~km}$, 起点在长岭陂水库溢洪 道消力池出口, 由东向西经过塘朗村和平山村等, 与西丽水库溢洪道相交后折向南流, 在滨海沙河立 交桥处注人深圳湾 (图 1). 大沙河贯穿整个南山 区，连接羊(阳) 台山、塘朗山和滨海休闲带, 是深 
圳市重要的绿色生态廊道和创新走廊, 大学城、高 新技术园区和南山中心园区分布于两岸，流域开发 程度高，人口密度大，属于典型的城市建成区河 流. 该流域属亚热带海洋性气候，多年平均气温 $22.4{ }^{\circ} \mathrm{C}$, 平均年降水量为 $1981.0 \mathrm{~mm}$, 但年内雨 量分布不均, 其中, 汛期 4 至 9 月降水量占全年降 水量的 $85.3 \%$.

目前, 大沙河上游河岸以植物护岸和石笼护岸 为主, 河道有一定蜿蜒度, 河道底质主要为砾石; 中上游河岸以植生型混凝土护岸为主，水量大，水 面宽, 底质多为堆积的泥沙沉积物; 中游河岸以草 地、灌木为主，水量少，底质以泥沙为主; 下游河 岸连接深圳湾公园, 河道笔直, 河岸硬质化现象严 重, 水体流动性差. 大沙河两岸已铺设截污箱涵, 且上游河段建有两处污水处理装置, 分别位于南方 科技大学校内及大学城河段, 污水处理量为 $1 \times 10^{4}$ $\mathrm{m}^{3} / \mathrm{d}$ 和 $4 \times 10^{3} \mathrm{~m}^{3} / \mathrm{d}$, 出水进人大沙河. 此外, 在 西丽水库溢洪道处引人西丽再生水厂尾水 $5 \times 10^{4}$ $\mathrm{m}^{3} / \mathrm{d}$ 补人大沙河. 大沙河中下游共有 4 座闸, 形 成南科大学段、大学城段以及河口段 3 处景观水 面, 水量约为 $6.4 \times 10^{5} \mathrm{~m}^{3}$.

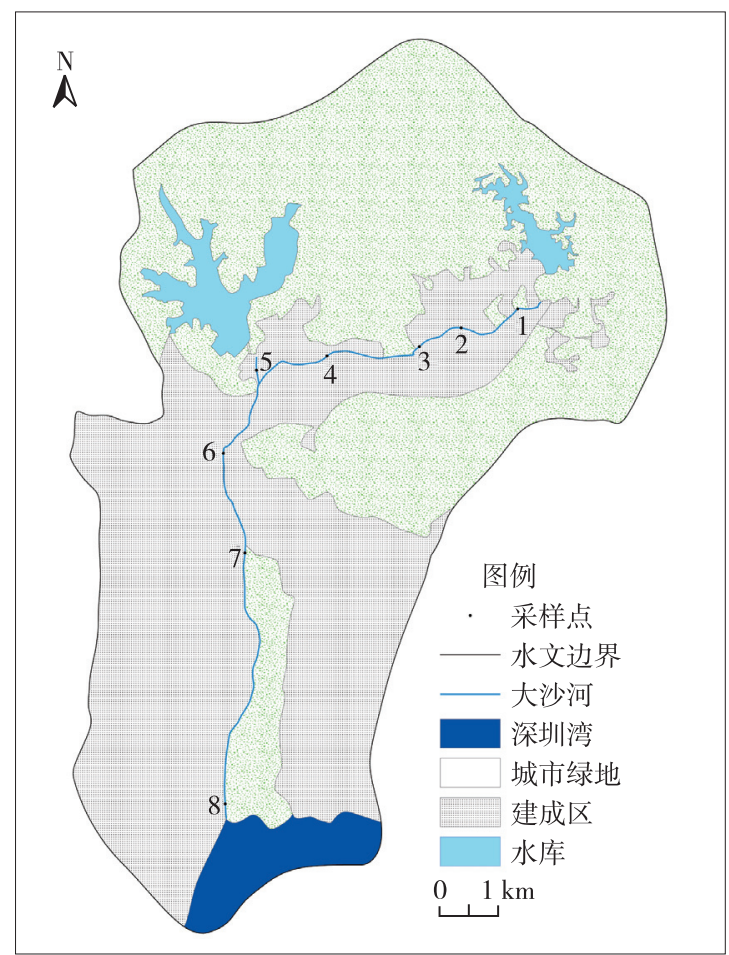

图 1 深圳市大沙河流域概况和采样点分布

Fig. 1 (Color online) The general situation and the distribution of the sampling points in the Dasha River basin in Shenzhen

\section{2 研究方法}

目前，河流生态功能评价的空间尺度往往较 大，如流域和区域尺度，其评价结果相对宏观，在 管理上难以实施 ${ }^{[20-21]}$. 针对这一不足以及大沙河的 实际状况, 为尽可能准确地评估大沙河的生态功能 状况，划分以下 4 个空间区域:

上游：长岭陂水库至大学城景观水面上游区域 (存在两处污水处理装置, 河道渠道化严重, 水面 窄，流速快）.

中上游：大学城景观水面区域（两端存在雍水 堰或翻板闸，水体深，水面宽，流速缓).

中游：大学城下游至大沙河公园区域（河道较 为自然, 水量较少, 有一定流速).

下游：大沙河河口感潮河段区域（水体深，水 面宽, 河口处设置钢闸, 本研究暂不考虑潮汐对河 流生态功能的影响).

从上游至下游共设置了 8 个采样点（表 1 ）, 各采样点位置见图 1. 并于 2018 年 1 月至 2019 年 1 月对各区域流域背景、河流地貌、水质状况、浮游 动植物、底栖动物、鱼类和植被等内容进行了现场 调查、采样和分析.

表 1 深圳市大沙河生态调查采样点设置

Table1 Sampling sites for ecological investigation of the Dasha River in Shenzhen

\begin{tabular}{cc}
\hline 采样区域 & 位 置 \\
\hline 上游 & 南方科技大学污水处理装置出水口 \\
& 深圳大学西丽校区 \\
& 西丽高尔夫球场 \\
\hline 中上游 & 清华大学研究生院 \\
\hline 中游 & 西丽再生水厂出水口 \\
& 南山文理实验学校 \\
& 大沙河公园 \\
\hline 下游 & 大沙河深圳湾河口 \\
\hline
\end{tabular}

3 大沙河生态功能评价

3.1 评价指标体系的建立

本研究结合已有的研究和实地调查情况, 选取 以水文支持功能、水环境支持功能、生境维持功能 
和水生生物多样性维持功能为主的指标评价系统, 依据指标数据的代表性、可获取性和评价方法的可 操作性, 选取与河流水生生物密切相关的 10 项评 价指标、14 项评价指数构建生态功能指标评价体 系. 为了突出评价指标体系中各指标、指数的差异 性和重要性，通过层次分析法获得指标和指数的权 重 ${ }^{[22-23]}$, 将评价指数的分值加权求和获得指标层分 值, 进一步由指标层加权求和获得功能层分值. 层 次分析法本质上是一种 “分解一判断一综合” 的基 本决策思维过程，保证了评价指标权重的合理性. 层次分析法主要步骤如下: (1) 建立递阶层次结构: 根据属性的不同对评价指标进行分类组合，形成一
种 “目标层一指标层一指数层” 递阶层次结构. 2 构造两两比较判断矩阵: 指标层的各方面因素进行 两两比较, 对重要性进行赋值, 据此构建指标层的 判断矩阵. 照此构建各指数层的判断矩阵. (3) 层 次单排序: 计算构建的指标层, 判断矩阵的最大特 征根及对应的特征向量, 得出 3 个指标层对应目标 层所占权重，同理计算出各具体指数对应指标层所 占的权重, 然后进行层次单排序分析. (4) 层次总 排序：层次总排序是指在层次单排序的基础上，综 合分析得出指数层对于目标层的相对重要性权值. 深圳市大沙河河流生态功能评价指标体系构成见 表 2.

表 2 深圳市大沙河生态功能评价指标体系 ${ }^{1)}$

Table 2 Evaluation indices of river ecological function of the Dasha River in Shenzhen

\begin{tabular}{|c|c|c|c|c|c|c|}
\hline 生态功能 & 评价指标 & 指标权重 & 指标含义 & 评价指数 & 指数权重 & 数据来源 \\
\hline \multirow{3}{*}{$\begin{array}{l}\text { 水生生物 } \\
\text { 多样性 } \\
\text { 维持功能 }\end{array}$} & 底栖动物多样性 & 0.30 & \multicolumn{2}{|c|}{ 反映河流底栖水生生物耐受指标 香农多样性指数 $(H)$} & 1 & 野外调查 \\
\hline & 浮游动植物多样性 & 0.30 & \multicolumn{2}{|c|}{ 反映河流浮游水生生物耐受指标香农多样性指数 $\left(H^{\prime}\right)$} & 取两者平均分 & 野外调查 \\
\hline & 鱼类稀有性 & 0.40 & 反映河段内稀有鱼种的丰富度 & 稀有性指数 $(C)$ & 1 & 野外调查 \\
\hline \multirow{4}{*}{$\begin{array}{c}\text { 生境 } \\
\text { 维持功能 }\end{array}$} & 生境自然性 & 0.20 & 表示河道生境受人类影响的程度 & $\begin{array}{c}\text { 河道河岸带形态描述 } \\
\text { 河道连通状况描述 }\end{array}$ & $\begin{array}{l}0.5 \\
0.5\end{array}$ & $\begin{array}{l}\text { 野外调查 } \\
\text { 野外调查 }\end{array}$ \\
\hline & 生境多样性 & 0.15 & $\begin{array}{c}\text { 指河道形态的复杂性和 } \\
\text { 河岸带景观多样性 }\end{array}$ & $\begin{array}{c}\text { 河流蜿蜒度 } \\
\text { 景观多样性指数 }(P)\end{array}$ & $\begin{array}{l}\text { 取二者 } \\
\text { 最大者 }\end{array}$ & $\begin{array}{l}\text { 野外调查与 } \\
\text { 历史资料 }\end{array}$ \\
\hline & 生境重要性 & 0.50 & 反映区域水生态的重要特征 & $\begin{array}{l}\text { 生物重要生境描述 } \\
\text { 河岸植被覆盖度 }\end{array}$ & $\begin{array}{l}0.8 \\
0.2\end{array}$ & $\begin{array}{l}\text { 野外调查 } \\
\text { 野外调查 }\end{array}$ \\
\hline & 滨岸带稳定性 & 0.15 & 为生境和河道提供缓冲作用 & $\begin{array}{c}\text { 河岸稳定性描述 } \\
\text { 护岸形式描述 }\end{array}$ & $\begin{array}{l}0.5 \\
0.5\end{array}$ & $\begin{array}{l}\text { 野外调查 } \\
\text { 野外调查 }\end{array}$ \\
\hline $\begin{array}{l}\text { 水环境 } \\
\text { 支持功能 }\end{array}$ & 水质级别 & 1.00 & $\begin{array}{c}\text { 表示河流为水生生物 } \\
\text { 提供生存环境能力 }\end{array}$ & 水质参数浓度得分 & 取各项平均分 & 野外调查 \\
\hline \multirow{2}{*}{$\begin{array}{l}\text { 水文支持 } \\
\text { 功能 }\end{array}$} & 流速状况 & 0.50 & 重要的水文参数 & 水流状况得分 & 1 & 野外调查 \\
\hline & 水量状况 & 0.50 & 保障水生态系统存在的基本条件 & 水量状况得分 & 1 & 野外调查 \\
\hline
\end{tabular}

1) 香农多样性指数: $H$ 或 $H^{\prime}=-\sum_{i}\left(P_{i} \ln P_{i}\right), P_{i}$ 为物种 $i$ 的相对丰富度; 鱼类稀有性指数 $C=\sum_{i=1}^{n} N_{i} / \sum_{j=1}^{m} N_{j}, n$ 和 $N_{i}$ 分别为分析单元中稀有 物种数和第 $i$ 种稀有物种的数量, $m$ 和 $N_{j}$ 分别为保护区中稀有物种总数和第 $j$ 类物种在保护区的总数量; 景观多样性指数计算公式: $P=$ $22-\sum_{i}\left(P_{i}^{\prime} \ln P_{i}^{\prime}\right), P_{i}^{\prime}$ 为第 $i$ 类景观类型所占的面积比例, 计算范围为河道中泓线左右 $500 \mathrm{~m}$ 内.

\section{2 评价指数赋分标准}

多指标评价需要对每个指标设定评价等级和分 级标准，等级划分通常采用奇数制，如 5 级制和 3 级制, 而分类标准一般采用评分法 ${ }^{[24]}$. 针对已建 立的深圳市大沙河生态功能评价指标体系, 本研究 采用 5 级制分级标准, 包括定量分析和定性分析,
4 分表示最高等级, 0 分表示最低等级. 水质参数 包括化学需氧量 ( chemical oxygen demand, $\mathrm{COD}_{\mathrm{Cr}}$ )、 5 日生化需氧量 (bio-chemical oxygen demand in five days, $\left.\mathrm{BOD}_{5}\right)$ 、氨氮质量浓度 $\rho\left(\mathrm{NH}^{4+}-\mathrm{N}\right)$ 、溶解氧 （dissolved oxygen, DO) 质量浓度 $\rho(\mathrm{DO})$ 和总磷质 量浓度 $\rho(\mathrm{TP})$ ，具体指数赋分标准见表 3. 
表 3 深圳市大沙河生态评价指数赋分标准

Table 3 Score criteria of evaluation indicators of river ecological function in the Dasha River

\begin{tabular}{|c|c|c|c|c|c|}
\hline \multirow{2}{*}{ 评价指数 } & \multicolumn{5}{|c|}{ 赋分标准 } \\
\hline & 4 & 3 & 2 & 1 & 0 \\
\hline 底栖动物多样性指数 & $>3.0$ & $\leqslant 3.0$ & $\leqslant 2.0$ & $\leqslant 1.5$ & $\leqslant 1.0$ \\
\hline 浮游动植物多样性指数 & $>4.0$ & $\leqslant 4.0$ & $\leqslant 3.0$ & $\leqslant 2.0$ & $\leqslant 1.0$ \\
\hline $\begin{array}{c}\text { 鱼类稀有性指数 } \\
\text { 河道滨岸形态 }\end{array}$ & $\begin{array}{c}>0.4 \\
\text { 无渠化和淤积, } \\
\text { 河流保持自然形态 }\end{array}$ & $\begin{array}{c}\leqslant 0.4 \\
\text { 存在少量拓宽、 } \\
\text { 挖深河道等现象, } \\
\text { 无明显渠化 }\end{array}$ & $\begin{array}{c}\quad \leqslant 0.3 \\
\text { 存在部分渠化, } \\
\text { 两岸筑有堤坝 }\end{array}$ & $\begin{array}{c}\leqslant 0.2 \\
\text { 渠化严重, } \\
\text { 两岸筑有堤坝, } \\
\text { 河床未经渠化 }\end{array}$ & $\begin{array}{c}\leqslant 0.1 \\
\text { 渠化严重, 河岸、 } \\
\text { 河床都已渠化, 河 } \\
\text { 道内生境极大改变 }\end{array}$ \\
\hline 河道连通性 & $\begin{array}{c}\text { 无堰坝,生物迁徙 } \\
\text { 不受任何阻碍 }\end{array}$ & $\begin{array}{c}\text { 建有少数小型 } \\
\text { 堰坝, 小型生物 } \\
\text { 迁徙受到一定阻碍 }\end{array}$ & $\begin{array}{l}\text { 建有一定数量中小 } \\
\text { 型堰坝,一定数量 } \\
\text { 生物迁徙受到阻碍 }\end{array}$ & $\begin{array}{c}\text { 建有大量堰坝或 } \\
\text { 大型水坝和水库, } \\
\text { 但有鱼道系统, } \\
\text { 生物迁徙受到 } \\
\text { 很大阻碍 }\end{array}$ & $\begin{array}{c}\text { 建有大型水坝 } \\
\text { 水库,无鱼道,生物 } \\
\text { 廊道受到完全阻碍 }\end{array}$ \\
\hline 河流蜿蜒程度 & $\begin{array}{l}\text { 保留自然弯曲状 } \\
\text { 态, 未经截弯取直 }\end{array}$ & $\begin{array}{c}\text { 截弯取直后进行了 } \\
\text { 较大程度恢复 } \\
(\geqslant 60 \%)\end{array}$ & $\begin{array}{c}\text { 截弯取直后进行了 } \\
\text { 一定程度恢复 } \\
(\geqslant 30 \%)\end{array}$ & $\begin{array}{c}\text { 截弯取直后进行了 } \\
\text { 较小程度的恢复 } \\
(\geqslant 10 \%)\end{array}$ & $\begin{array}{c}\text { 经过截弯取直, } \\
\text { 河流笔直 }\end{array}$ \\
\hline 河岸带景观多样性 & $>1.5$ & $\leqslant 1.5$ & $\leqslant 1.3$ & $\leqslant 1.2$ & $\leqslant 1.1$ \\
\hline 河流护岸形式 & $\begin{array}{c}\text { 有植被覆盖的 } \\
\text { 自然土质岸 }\end{array}$ & $\begin{array}{c}\text { 近自然的 } \\
\text { 斜坡式生态护岸 }\end{array}$ & $\begin{array}{l}\text { 亲水平台护岸或 } \\
\text { 无植被的土质岸坡 }\end{array}$ & $\begin{array}{c}\text { 台阶式人工护岸或 } \\
\text { 浆砌块石护岸 }\end{array}$ & $\begin{array}{l}\text { 直立式钢筋 } \\
\text { 混凝土护岸 }\end{array}$ \\
\hline 河岸稳定性 & $\begin{array}{l}\text { 河岸稳定, } \\
\text { 无明显侵蚀 }\end{array}$ & $\begin{array}{c}\text { 河岸稳定,少量 } \\
\text { 区域存在侵蚀 } \\
(<20 \%)\end{array}$ & $\begin{array}{c}\text { 河岸较不稳定, } \\
\text { 中度侵蚀 } \\
(20 \% \sim 50 \%)\end{array}$ & $\begin{array}{l}\text { 河岸不稳定, 极度 } \\
\text { 侵蚀, 洪水时存在 } \\
\text { 风险 }(50 \% \sim 80 \%)\end{array}$ & $\begin{array}{c}\text { 河岸极不稳定, } \\
\text { 绝大部分区域侵蚀 } \\
(80 \% \sim 100 \%)\end{array}$ \\
\hline 重要生境价值 & $\begin{array}{c}\text { 具有国际和国家 } \\
\text { 一级保护物种避 } \\
\text { 难所、保育所、 } \\
\text { 索饵所和产卵所 }\end{array}$ & $\begin{array}{c}\text { 具有国家二级 } \\
\text { 保护物种避难所、 } \\
\text { 保育所、索饵所和 } \\
\text { 产卵所 }\end{array}$ & $\begin{array}{c}\text { 一般物种的 } \\
\text { 避难所、保育所、 } \\
\text { 索饵所和产卵所 }\end{array}$ & $\begin{array}{l}\text { 水生生物的 } \\
\text { 重要活动场所 }\end{array}$ & $\begin{array}{c}\text { 水生生物的 } \\
\text { 非重要活动场所 }\end{array}$ \\
\hline 植被覆盖河岸比例 & $95 \% \sim 100 \%$ & $80 \% \sim 94 \%$ & $65 \% \sim 79 \%$ & $40 \% \sim 64 \%$ & $0 \sim 39 \%$ \\
\hline $\begin{array}{l}\text { 水质参数/ } \\
\left(\mathrm{mg} \cdot \mathrm{L}^{-1}\right)\end{array}$ & $\begin{array}{c}\rho\left(\mathrm{COD}_{\mathrm{Cr}}\right) \leqslant 15.0 ; \\
\rho\left(\mathrm{BOD}_{5}\right) \leqslant 3.0 ; \\
\rho\left(\mathrm{NH}^{4+}-\mathrm{N}\right) \leqslant 1.0 ; \\
\rho(\mathrm{DO}) \geqslant 7.5 ; \\
\rho(\mathrm{TP}) \leqslant 0.05\end{array}$ & $\begin{array}{c}\rho\left(\mathrm{COD}_{\mathrm{Cr}}\right) \leqslant 20.0 ; \\
\rho\left(\mathrm{BOD}_{5}\right) \leqslant 4.0 ; \\
\rho\left(\mathrm{NH}^{4+}-\mathrm{N}\right) \leqslant 1.5 ; \\
\rho(\mathrm{DO}) \geqslant 6.0 ; \\
\rho(\mathrm{TP}) \leqslant 0.1\end{array}$ & $\begin{array}{c}\rho\left(\mathrm{COD}_{\mathrm{Cr}}\right) \leqslant 30.0 ; \\
\rho\left(\mathrm{BOD}_{5}\right) \leqslant 4.0 ; \\
\rho\left(\mathrm{NH}^{4+}-\mathrm{N}\right) \leqslant 2.0 ; \\
\rho(\mathrm{DO}) \geqslant 5.0 ; \\
\rho(\mathrm{TP}) \leqslant 0.2\end{array}$ & $\begin{array}{c}\rho\left(\mathrm{COD}_{\mathrm{Cr}}\right) \leqslant 40.0 ; \\
\rho\left(\mathrm{BOD}_{5}\right) \leqslant 10.0 ; \\
\rho\left(\mathrm{NH}^{4+}-\mathrm{N}\right) \leqslant 8.0 ; \\
\rho(\mathrm{DO}) \geqslant 3.0 ; \\
\rho(\mathrm{TP}) \leqslant 0.5\end{array}$ & $\begin{array}{c}\rho\left(\mathrm{COD}_{\mathrm{Cr}}\right)>40.0 ; \\
\rho\left(\mathrm{BOD}_{5}\right)>10.0 ; \\
\rho\left(\mathrm{NH}^{4+}-\mathrm{N}\right)>8.0 ; \\
\rho(\mathrm{DO}) \leqslant 2.0 ; \\
\rho(\mathrm{TP})>0.5\end{array}$ \\
\hline 流速状况 & $\begin{array}{c}\text { 两头通, } \\
\text { 具有一定流速, } \\
\text { 各断面流速不均 }\end{array}$ & $\begin{array}{c}\text { 两头通,流速 } \\
\text { 较为均一,各断面 } \\
\text { 流速略有变化 }\end{array}$ & $\begin{array}{l}\text { 两头通,流速 } \\
\text { 均一,各断面 } \\
\text { 流速无变化 }\end{array}$ & $\begin{array}{l}\text { 河流一头通, } \\
\text { 水体流动受阻 }\end{array}$ & $\begin{array}{c}\text { 水体不流动, } \\
\text { 与其他河流隔离 }\end{array}$ \\
\hline 水量状况 & $\begin{array}{c}\text { 水位达到两岸, } \\
\text { 仅有少量底质裸露 }\end{array}$ & $\begin{array}{l}\text { 水覆盖 }>75 \% ; \\
<25 \% \text { 底质裸露 }\end{array}$ & $\begin{array}{c}\text { 水覆盖 } 50 \% \text { } \\
75 \% ;<50 \% \text { 的 } \\
\text { 底质裸露 }\end{array}$ & $\begin{array}{l}\text { 水覆盖 }<25 \%, \\
\text { 浅滩大部分裸露 }\end{array}$ & $\begin{array}{l}\text { 水量很少, 底质 } \\
\text { 几乎全部裸露 }\end{array}$ \\
\hline
\end{tabular}




\section{3 评判标准}

按照城市建成区河流生态系统健康状况及演变 规律, 结合研究区现有情况并参考相关文献, 采用 直观分析与对比的区间分层方式 ${ }^{[18]}$, 将大沙河不 同区段的生态功能由高到低依次划分为健全、较健 全、部分生态功能受到威胁与只具备最基本的生态 功能 4 个评价等级 (表 4 ).

表 4 大沙河不同河段生态功能等级标准

Table 4 The standard of the ecological function of the different reaches of the Dashe River

\begin{tabular}{|c|c|c|c|}
\hline 功能等级 & 分值区间 & 生态特征 & 功能特征 \\
\hline I & $12 \sim 16$ & $\begin{array}{l}\text { 水生态系统不受 } \\
\text { 或很少受人类活 } \\
\text { 动干扰 }\end{array}$ & $\begin{array}{l}\text { 生态功能 } \\
\text { 健全 }\end{array}$ \\
\hline II & $10 \sim 12$ & $\begin{array}{l}\text { 水生态系统受到 } \\
\text { 较小程度的人类 } \\
\text { 活动干扰 }\end{array}$ & $\begin{array}{l}\text { 生态功能 } \\
\text { 较健全 }\end{array}$ \\
\hline III & $8 \sim 10$ & $\begin{array}{l}\text { 水生态系统受到 } \\
\text { 较大程度的人类 } \\
\text { 活动干扰 }\end{array}$ & $\begin{array}{l}\text { 部分生态 } \\
\text { 功能受到 } \\
\text { 威胁 }\end{array}$ \\
\hline IV & $\leqslant 8$ & $\begin{array}{l}\text { 水生态系统受到 } \\
\text { 很大程度的人类 } \\
\text { 活动干扰 }\end{array}$ & $\begin{array}{l}\text { 只具备最 } \\
\text { 基本的生 } \\
\text { 态功能 }\end{array}$ \\
\hline
\end{tabular}

\section{4 结果与分析}

\section{1 大沙河生态调查结果}

水质监测结果显示: 大沙河全河段的 $\rho(\mathrm{DO})$ 为 $5.22 \sim 8.12 \mathrm{mg} / \mathrm{L} 、 \rho\left(\mathrm{COD}_{\mathrm{Cr}}\right)$ 为 $15.75 \sim 45.33$ $\mathrm{mg} / \mathrm{L} 、 \rho\left(\mathrm{BOD}_{5}\right)$ 为 $2.77 \sim 5.73 \mathrm{mg} / \mathrm{L} 、 \rho\left(\mathrm{NH}^{4+}-\mathrm{N}\right)$ 为 $0.66 \sim 7.66 \mathrm{mg} / \mathrm{L} 、 \rho(\mathrm{TP})$ 为 $0.43 \sim 0.93 \mathrm{mg} / \mathrm{L}$, 不同河段水质变化较大. 分别于 2018 年 $1 、 3 、 6$ 和 9 月 4 次调查, 共采集到大型底栖动物共 12 种. 其中, 腹足类软体动物 6 种、双壳类软体动物 2 种、环节动物 2 种、甲壳动物虾类 2 种. 中游河段 底栖动物物种相对丰富, 所采集到的总个体数量也 较中上游更多, 香农-维纳 (Shannon-Weiner) 生物多 样性指数在 $1.024 \sim 1.457$, 表明所有河段的底栖动 物多样性均偏低, 群落丰富度不高. 各采样点共鉴 定浮游植物 7 门 50 种 (属). 其中, 优势的门类为 硅藻门 18 种、绿藻门 14 种、蓝藻门 10 种, 优势
种以硅藻门的舟形藻、小环藻和脆杆藻, 蓝藻门的 隐杆藻和伪鱼腥藻, 裸藻门的裸藻为主, ShannonWeiner 多样性指数为 $0.229 \sim 2.860$, 符合中度到重 度污染水体的特征. 各采样点浮游动物共鉴定 7 门 17 个种 (属), 其中, 上游的优势种为节肢动物门 桡足类、枝角类和摇蚊幼虫，中游出现水溞、水螅 等清洁水体指示种, 表明中游河段水质较好. 下游 感潮河段的优势种为节肢动物门的无节幼虫，与深 圳湾的甲壳类藤壶等生物出现有关. 调查中共采集 鱼类 16 种，隶属于 6 目 9 科 14 属. 其中, 鲤形目 有 3 科 7 属 8 种，占种数的 $50 \%$. 值得关注的是， 其中，有 4 个种类属于外来种（引人种）, 包括尼 罗口孵非鲫、莫桑比克口孵非鲫、食蚊鱼及下口 鲇, 且优势种为尼罗口孵非鲫和莫桑比克口孵非 鲫，外来种占本调查渔获总种类的 $25 \%$, 该比例远 高于国内其他河流 ${ }^{[25]}$.

\section{2 生态功能评价结果}

按照第 3 章所述生态功能评价方法, 最终得到 大沙河流域综合生态功能等级结果为: 全流域不存 在 I 级河段, 上游和上中游受到较大程度人类活动 的影响, 为 III 级河段; 中游具有较健全的生态功 能, 属于 II 河段; 下游受人为影响严重, 只具备最 基本的生态功能, 为 $\mathrm{IV}$ 河段.

大沙河各河段具体的生态功能分析如下：上游 和中上游的水面覆盖率较大, 具有一定流速, 且水 质较好, 因此, 水文支持功能和水环境支持功能较 高; 但河道存在一定的渠道化, 建有一定数量的中 小型堰坝, 部分生物迁移受阻, 水生生物多样性较 低, 因此, 生境维持功能和水生生物多样性维持功 能较低(图 $2(\mathrm{a})$ 和 $(\mathrm{b})$ ).

大沙河中游保留着一定程度的自然状态, 河道 虽有少量的截弯取直和拓宽, 但护岸是有植被覆盖 的自然土质岸坡（植被覆盖率达到 $80 \%$ 以上), 植 被多样性较丰富, 无落差大的堰坝, 生物的迁移没 有受到阻碍, 水质较好, 水生生物种类、数量相对 较多, 因此, 该河段具有良好的生境维持和水环境 维持功能 (图 $2(\mathrm{c})$ ).

大沙河下游为河口感潮河段, 水量大, 但早期 由于考虑河道行洪排涝的功能, 采用浆砌块石或混 凝土硬质河岸, 导致其生境维持功能很低. 此外, 受到河口水闸的影响, 水体流动受阻. 因此, 下游 虽具有较高的水文支持功能, 但生境维持和水生生 物多样性维持功能较低(图 2(d)). 


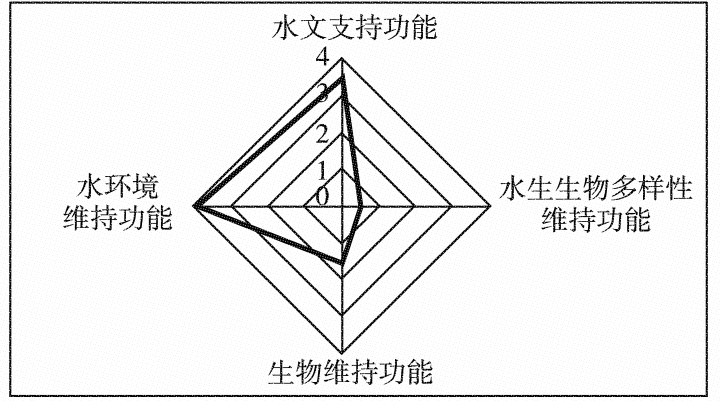

(a) 大沙河上游

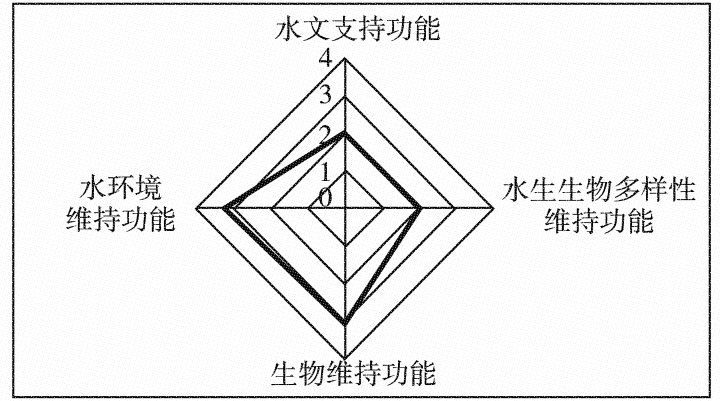

(c) 大沙河中游

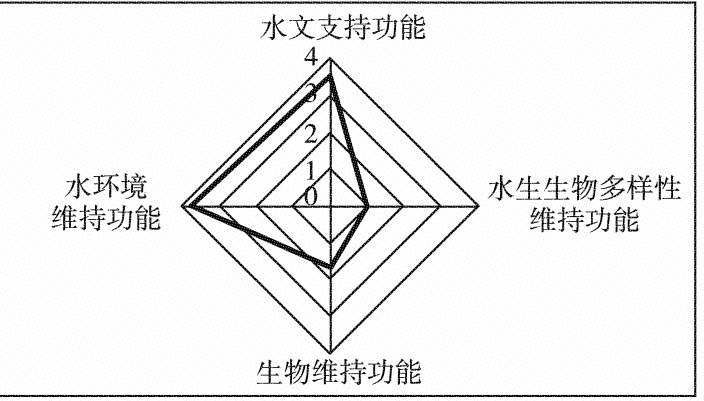

(b) 大沙河中上游

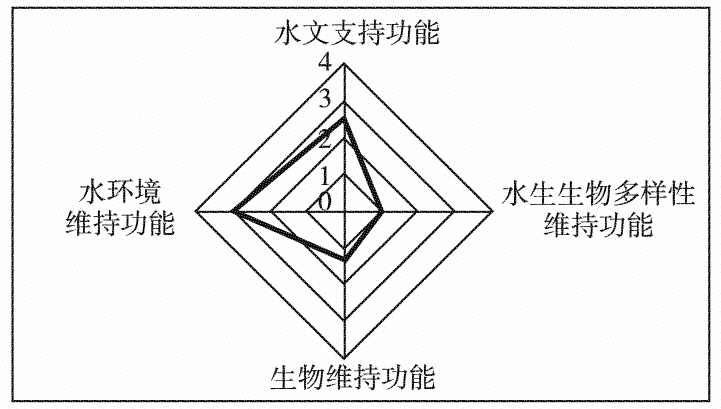

(d) 大沙河下游

图 2 大沙河各河段生态功能评价结果

Fig. 2 Evaluation results of ecological function in each reach of the Dasha River

\section{3 大沙河生态修复对策}

\subsection{1 河段生态修复策略}

上游段长岭陂水库-大学城景观水面上游区域, 河段渠道化程度高, 受行洪影响导致生态涵养能力 低，污水净化系统出水仍残留有较高的总氮，石笼 护岸植被覆盖率不高, 部分河床硬质化, 生境多样 性差. 针对这些问题，采用生态袋设置耐冲击植物 斑块, 保障生物通道的水量、水深和流速, 优化水 流路径和停留时间；提升污水净化系统脱氮效率或 利用人工湿地进行尾水深度处理 ${ }^{[26]}$; 优选根系发 达，能固坡、防止泥土流失和耐冲刷的植物品种修 复护岸植被, 并配置一定比例的生境庇护所.

中上游大学城区域河段存在雍水堰或翻板闸, 形成了具有景观效果的雍水段，但水体流动受阻， $\rho(\mathrm{TN})$ 和 $\rho(\mathrm{TP})$ 较高, 呈现富营养化趋势, 水体透 明度较低, 基本无水生植被, 生物多样性差. 建议 利用两岸绿地空间, 配置净化型湿地系统; 在水中 利用沉水、浮叶植物进行原位修复，抑制藻类水华 演化趋势.

中游大学城下游-大沙河公园段是大沙河流域 生态功能最为健全的河段, 但也存在补水水质氮、 磷含量高, 河道水量少, 部分河床底质裸露, 岸坡 植被多样性不高等问题. 针对此现状，建议利用两
岸绿地空间及水势, 配置分布式净化湿地系统, 设 置区段内循环回流系统, 强化对 TN 和 TP 的去除, 同时提高水面覆盖率. 此外，可结合周边用地情 况, 建设湿地/塘系统, 该系统应设置在河流行洪 影响范围以外, 可作为生物种质资源库, 辅助河道 生物多样性恢复，特别是敏感型生物物种复育，同 时该系统还具备雨洪调蓄、水质净化和生境构筑等 多项功能，是一项生态服务价值高的行洪河道修复 策略.

下游河口段存在河道渠道化严重，多样化生境 少, 河口闸阻碍鱼类洄游等问题. 可利用河口连接 深圳湾的有利条件，建设河口智慧闸坝，根据涨落 潮调控水闸, 吸引深圳湾各水层鱼类进人大沙河, 提升鱼类多样性; 水面设置生态浮岛、水下构筑鱼 巢, 为水鸟及水生生物提供停歇、栖息场所.

\subsection{2 河段生态管理策略}

生态修复工程的成效与后续的管理存在密切关 系，包括对污染物的管理、生物管理、生态系统的 调控和市民的科普教育等多个维度, 需要多个部门 与专业人员密切配合和协调工作. 因而，针对大沙 河生态系统管理有以下建议:

1) 建立完善的水生态数据信息平台. 为保障 生态系统长期、健康地演化发展，需长期跟踪监测 
水文、水质和水生生物变化, 建设完善的水生态监 测网络、水生态管理、环境灾害响应应急平台等信 息系统，为大沙河生态管理提供决策支持.

2) 建立科学的河流生态系统运行管理体系. 通过量化污染物输人量、净化量, 加强生物物种管 理, 并制定生态友好型的河流生态管理规范与操作 规程, 指导生态系统的调控和运行, 引导生态系统 正向演替.

3) 建立多部门公共管理机制. 生态系统的 “养” 重于 “建”, 生态系统的日常管理需要民众 的广泛参与. 由河流管理部门主导, 联合专家团 队, 招募志愿者参与生态系统日常管理, 联动社区 居民、学生参与体验, 开展线上-线下城市课堂等 多主题的科普教育, 发挥河流生态系统的环境教育 功能.

\section{结 语}

本研究对深圳市大沙河流域水生生物多样性和 各相关因素进行了全面的调查、采样和分析, 获得 了大沙河流域的水质、水生生物物种资源和生境胁 迫因素等状况的基底数据, 并对大沙河生态功能现 状进行了评价. 结果表明: 大沙河无 I 级河段, II 级河段仅为中游区域，上游和中上游区域为 III 级河 段, 下游河口段仅具备最基本的生态功能, 为 $\mathrm{IV}$ 级 河段. 针对各河段存在的问题, 提出了针对性的修 复策略, 并从污染物的管理、生态系统的调控、市 民的科普教育等多个维度对城市建成区河流生态系 统的管理提出了针对性建议.

致谢: 衣心感谢深圳大学邓利教授、雷安平教授、张永夏 副教授、陈辉蓉老师和张爆老师对浮游植物、浮游 动物、底栖动物、鱼类和植被的鉴定与分析的指导!

基金项目：国家海洋局 “十三五” 海洋经济示范市专项资助项目 (086); 深圳市知识创新计划基础研究资助项目 ( JCYJ20180207144018216)

作者简介: 付贵萍 $(1970-)$, 深圳大学教授级高级工程师. 研究 方向: 生物净化与生态修复. E-mail: fugp@ szu.edu.cn

引文：付贵萍，赵 林，武金发，等. 城市建成区河流生态功 能评价及修复策略研究 $[\mathrm{J}]$. 深圳大学学报理工版, $2020,37(4)$ : 372-380.

\section{参考文献 / References:}

[ 1 ] CHEN W Y. Environmental externalities of urban river pollution and restoration: a hedonic analysis in Guangzhou (China) [J]. Landscape and Urban Planning, 2017,
$157(1): 170-179$

[2 ] PAN Guangbo, XU Youpeng, YU Zhihui, et al. Analysis of river health variation under the background of urbanization based on entropy weight and matter-element model: a case study in Huzhou City in the Yangtze River Delta, China [J]. Environmental Research, 2015, 139 (5) : 31-35.

[ 3 ] WEN Yingrong, SCHOUPS G, VAN DE GIESEN N. Organic pollution of rivers: combined threats of urbanization, livestock farming and global climate change $[\mathrm{J}]$. Scientific Reports, 2017, 7(1): 43289.

[ 4 ] HAN Longfei, XU Youpeng, LEI Chaogui, et al. Degrading river network due to urbanization in Yangtze River Delta $[\mathrm{J}]$. Journal of Geographical Sciences, 2016, 26(6) : 694-706.

[ 5 ] HOYER R, CHANG H J. Assessment of freshwater ecosystem services in the Tualatin and Yamhill basins under climate change and urbanization $[\mathrm{J}]$. Applied Geography, 2014, 53(9) : 402-416.

[6]江华锋. 城市河道综合整治工程及生态修复设计策略 [J]. 中国资源综合利，2019，37(8)：155-157.

JIANG Huafeng. Design strategy of urban river comprehensive regulation project and ecological restoration $[\mathrm{J}]$. China Resources Comprehensive Utilization, 2019, 37 (8) : 155-157. (in Chinese)

[ 7 ] 王 姝, 毛媛媛, 梁志蓉, 等. 重庆市城区段河流生 态修复后评价指标体系框架构建 $[\mathrm{J}]$. 环境影响评价, 2018, 40(4) : 39-42.

WANG Shu, MAO Yuanyuan, LIANG Zhirong, et al. Study on the evaluation indicator system of river ecological restoration in Chongqing $[\mathrm{J}]$. Environmental Impact Assessment, 2018, 40(4): 39-42. (in Chinese)

[ 8 ] MUNNÉ A, PRAT N, SOLÀ $\mathrm{C}$, et al. A simple field method for assessing the ecological quality of riparian habitat in rivers and streams: QBR index $[\mathrm{J}]$. Aquatic Conservation-Marine and Freshwater Ecosystems, 2003, 13(2) : 147-163.

[ 9 ] WRIGHT J F. Development and use of a system for predicting the macroinvertebrate fauna in flowing waters. Austral Ecology, 1995, 20(1) : 181-197.

[10] SIMS A, ZHANG Yanyan, GAJARAJ S, et al. Toward the development of microbial indicators for wetland assessment $[\mathrm{J}]$. Water Research, 2013, 47 ( 5 ): 17111725 .

[11] VERDONSCHOT P F M. Integrated ecological assessment methods as a basis for sustainable catchment management [J]. Hydrobiologia, 2000, 422/423 : 389-412.

[12] PETERSEN R C. The RCE: a riparian, channel, and 
environmental inventory for small streams in the agricultural landscape $[\mathrm{J}]$. Freshwater Biology, 1992, 27 (2) : 295-306.

[13］曹莉萍, 周冯琦, 吴 蒙. 基于城市群的流域生态补 偿机制研究一以长江流域为例 $[\mathrm{J}]$. 生态学报, 2019，39(1) : 85-96.

CAO Liping, ZHOU Fengqi, WU Meng. Study on the ecological compensation mechanism of a watershed based on an urban agglomeration by using the Yangtze River basin as an example $[\mathrm{J}]$. Acta Ecologica Sinica, 2019, 39(1) : 85-96. (in Chinese)

[14] 陈宇顺. 多重人类干扰下长江流域的水生态系统健康 修复 $[\mathrm{J}]$. 人民长江，2019，50(2)：19-23。

CHEN Yushun. Restoring aquatic ecosystem health of Yangtze River basin under multiple human disturbances [J]. Yangtze River, 2019, 50 (2): 19-23. (in Chinese)

[15] 李瑶瑶，于鲁冀，吕晓燕，等. 淮河流域（河南段） 河流生态系统健康评价及分类修复模式 $[\mathrm{J}]$. 环境科 学与技术，2016，39(7)：185-192.

LI Yaoyao, YU Luji, LU Xiaoyan, et al. Health evaluation and repairing mode on river ecosystem of Huaihe River basin (Henan sectio) [ J ]. Environmental Science \& Technology, 2016, 39(7) : 185-192. (in Chinese)

[16] 杨文杰，赵 越，赵康平，等. 流域水生态系统服务 价值评估研究一以黄山市新安江为例 $[\mathrm{J}]$ 。 中国环 境管理, 2018，10(4)：100-106.

YANG Wenjie, ZHAO Yue, ZHAO Kangping, et al. Evaluation on the ecosystem services value of the Xin'anjiang River in Huangshan [ J ]. Environmental Management of China, 2018, 10(4) : 100-106. (in Chinese)

[17] 万 峻, 刘红艳, 张 远, 等. 太子河流域河流生态功 能评价及其管理策略 $[\mathrm{J}]$ 。应用生态学报，2013，24 (10) : 2933-2940.

WAN Jun, LIU Hongyan, ZHANG Yuan, et al. Ecological function evaluation and related management strategies of river ecosystem in Taizi River basin, North China $[\mathrm{J}]$. Chinese Journal of Applied Ecology, 2013, 24 ( 10 ): 2933-2940. (in Chinese)

[18］曹 宸, 李叙勇. 区县尺度下的河流生态系统健康评 价一一北京房山区为例 $[\mathrm{J}]$. 生态学报, 2018, 38 (12) : 4296-4306.

CAO Chen, LI Xuyong. Health assessment of river ecosystem at the district and county scales: a case study of Fangshan district in Beijing $[\mathrm{J}]$. Acta Ecologica Sinica, 2018, 38(12) : 4296-4306. (in Chinese)

[19] 李 婧. 深圳市重点河流水环境现状与治理对策浅析
[J]. 广东化工, 2019，46(11) : 154-155.

LI Jing. Water environment and pollution control measures of main rivers in shenzhen city $[\mathrm{J}]$. Guangdong Chemical Industry, 2019，46(11) : 154-155. (in Chinese)

[20] 李云成, 王瑞玲, 娄广艳. 湟水流域水生态保护与修复 研究 $[\mathrm{J}]$. 水生态学杂志, $2017,38(6)$ : 11-18.

LI Yuncheng, WANG Ruiling, LOU Guangyan. Overall framework of water ecological protection and restoration in Huangshui River basin [ J ]. Journal of Hydroecology, 2017, 38(6) : 11-18. (in Chinese)

[21] 彭 勃, 王化儒, 王瑞玲, 等. 黄河下游河流健康评估 指标体系研究 $[\mathrm{J}]$. 水生态学杂志, $2014,35(6)$ : 8187.

PENG Bo, WANG Huaru, WANG Ruiling, et al. Development of a river health assessment system for the lower Yellow River [J]. Journal of Hydroecology, 2014 35(6) : 81-87. (in Chinese)

[22] 郑 保, 罗文胜. 河流生态系统健康评价指标体系及 权重的研究 $[\mathrm{J}]$. 水电与新能源, $2019,33(8)$ ：6065 .

ZHEN Bao, LUO Wensheng. On the health evaluation index system and weight of river ecosystem $[\mathrm{J}]$. Hydropower and New Energy, 2019, 33 (8) : 60-65. (in Chinese)

[23］陆海田．河流健康评价指标权重分析 $[\mathrm{J}]$. 水资源开 发与管理，2018，9(9)：14-18.

LU Haitian. Weight analysis of river health evaluation index $[\mathrm{J}]$. Water Resources Development and Management, 2018, 9(9): 14-18. (in Chinese)

[24] 陈 歆, 靳甜甜, 苏辉东, 等. 拉萨河河流健康评价指 标体系构建及应用 $[\mathrm{J}]$ 。生态学报，2019，39（3)： 799-809.

CHEN Xin, JIN Tiantian, SU Huidong, et al. Construction and application of health assessment index system for Lhasa River [J]. Acta Ecologica Sinica, 2019, 39(3) : 799-809. (in Chinese)

[25] YANG Zhipu, LU Qiqi. Exotic fish potential hazards in dongguan reaches of Dongjiang River and its coping strategies $[\mathrm{J}]$. Journal of Green Science and Technology, 2016(10) : 149-151.

[26] 乔群博. 人工湿地在城市景观河流应用中存在的问题 及解决措施 $[\mathrm{J}]$. 黑龙江科学，2017，8(12)：16-17. QIAO Qunbo. Problems and solutions of application of constructed wetland in urban landscape river $[\mathrm{J}]$. Heilongjiang Science, 2017, 8(12): 16-17. (in Chinese)

【中文责编：晨 兮; 英文责编：艾 琳】 